Check for updates

Cite this: RSC Adv., 2017, 7, 49368

\title{
Effect of the relative permittivity of oxides on the performance of triboelectric nanogenerators $\dagger$
}

\author{
Yeon Joo Kim, Jaejun Lee, Sangwon Park, Chanho Park, Cheolmin Park \\ and Heon-Jin Choi $\mathbb{D}$ *
}

Since the working mechanism of triboelectric nanogenerators (TENGS) is based on triboelectrification and electrostatic induction, it is necessary to understand the effects of the inherent properties of dielectric materials on the performance of TENGs. In this study, the relationship between the relative permittivity and the performance of TENGs was demonstrated by fabricating TENGs using both pure oxide materials $\left(\mathrm{SiO}_{2}, \mathrm{Al}_{2} \mathrm{O}_{3}, \mathrm{HfO}_{2}, \mathrm{Ta}_{2} \mathrm{O}_{5}\right.$ and $\left.\mathrm{TiO}_{2}\right)$ and oxide-PMMA composites. As oxide materials and PMMA are triboelectrically positive, PTFE film was selected as the counter tribo-material, which has highly negative triboelectric polarity. The triboelectric series of the above-mentioned oxides was experimentally organized to clarify the major parameter for the performance of TENGs. The electrical data values for both oxides and composites clearly showed a tendency to increase as the relative permittivity of the tribo-material increased. It is also well-matched with the theoretical analysis between the electrical performances (e.g. open-circuit voltage) and relative permittivity. However, such a tendency is not observed with the triboelectric polarity. Due to the tribo-material's high relative permittivity, an opencircuit voltage of $124.1 \mathrm{~V}$, a short-circuit current of $14.88 \mu \mathrm{A}$ and a power of $392.08 \mu \mathrm{W}$ were obtained in a pure $\mathrm{TiO}_{2}$ thin film.

Received 1st July 2017

Accepted 11th October 2017

DOI: $10.1039 / \mathrm{c} 7 \mathrm{ra} 07274 \mathrm{k}$

rsc.li/rsc-advances determine the electrostatic charge generation, accumulation and transportation, which are crucial to the performance of TENGs. ${ }^{5,24-26}$

However, limited studies have been done on these parameters, and more studies must be done to clearly understand the effect of the parameters of the material. ${ }^{27-29}$ For example, Jie Chen et al. demonstrated the influence of the effective relative permittivity of materials on the output performance of conductor-to-dielectric contact mode TENGs. ${ }^{26}$ However, since PDMS composites were used as the tribo-materials, and the effective relative permittivity was calculated using volumetric fractions of the matrix and filling materials, this method could not clearly address the effect of permittivity.

Herein, we present dielectric-to-dielectric contact mode TENGs using both pure dielectric oxide thin films and oxidePMMA composites. The influence of the two critical parameters, dielectricity and triboelectric polarity, on the output performance is discussed experimentally and theoretically. The results indicate that both the surface charge density and the charge transfer quantity, which are important for the performance of TENGs, are dependent on the relative permittivity of the tribo-materials.
Department of Materials Science and Engineering, Yonsei University, 03722, Seoul, South Korea.E-mail: hjc@yonsei.ac.kr

$\dagger$ Electronic supplementary information (ESI) available. See DOI: $10.1039 / \mathrm{c} 7 \mathrm{ra} 07274 \mathrm{k}$

\section{Results and discussion}

A schematic design of the layered structure of TENGs is shown in Fig. 1a. In this study, the dielectric-to-dielectric contact-mode 

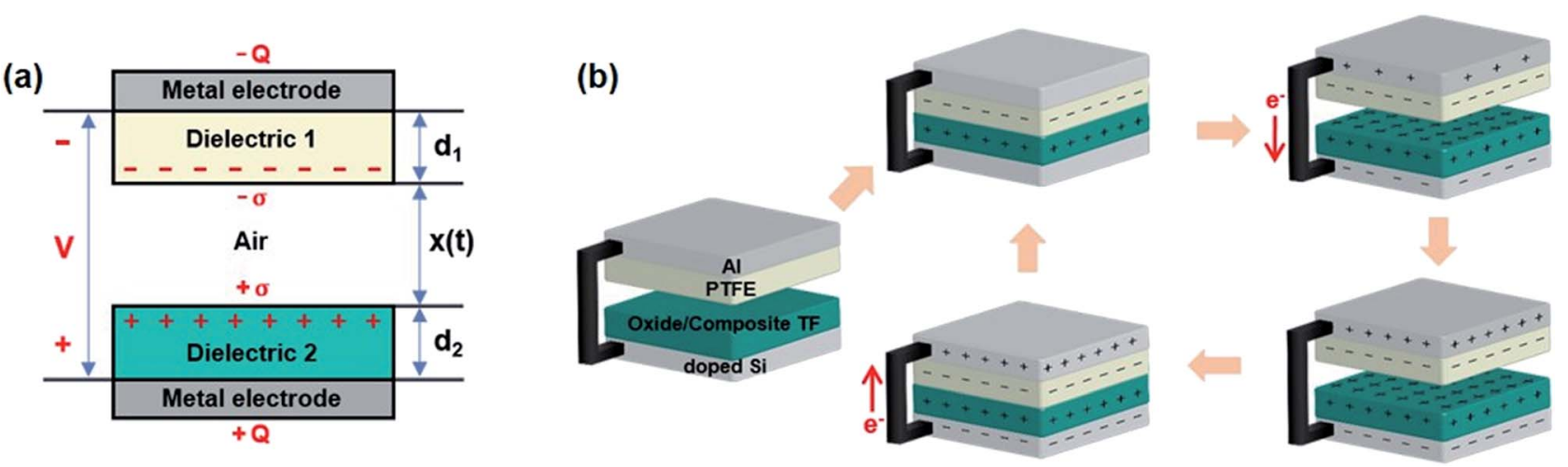

Fig. 1 The working mechanism of TENGs. (a) Device design. The dielectric-dielectric model is used. Dielectric 1 is a commercial PTFE film with $50 \mu \mathrm{m}$ thickness. Dielectric 2 is a layer of deposited thin film of different oxide dielectric materials with different dielectric constants. (b) Electricity generation is achieved from the repetitive contact of two different materials.

is used. PTFE film $(50 \mu \mathrm{m})$ was chosen as a negative tribomaterial, and sputter-deposited oxide thin films $(300 \mathrm{~nm})$, with a different relative permittivity, were chosen as positive tribo-materials, which are referred to as dielectric 1 and dielectric 2 in Fig. 1a, respectively. Fig. 1b illustrates the working mechanism of TENGs under a vertical load. In the initial state, there is no charge transfer between the two plates, and thus electric potential does not exist. When the top plate is pressed and the two tribo-materials contact, electrons transfer from the positive material to the negative material. Once the load is removed, the two plates are separated and an electric potential difference is established between the two plates. The electric potential difference works as a driving force of electron flow from the negative plate to the positive plate through the electrode. Upon applying the external load, the existing electric potential difference diminishes and the electric outputs, such as the open-circuit voltage $\left(V_{\mathrm{oc}}\right)$ and short-circuit current $\left(I_{\mathrm{sc}}\right)$, are measured from the electron flow. This process is repeated upon repetitive contact in a working device. From previous work by the Zhong Lin Wang group, ${ }^{10}$ the voltage of the dielectric-todielectric model in the contact mode can be given by

$$
V=-\frac{\Delta \sigma}{\varepsilon_{0}}\left(\frac{d_{1}}{\varepsilon_{\mathrm{r} 1}}+\frac{d_{2}}{\varepsilon_{\mathrm{r} 2}}+x(t)\right)+\frac{\sigma x(t)}{\varepsilon_{0}}
$$

where $\sigma, \varepsilon_{0}$ and $x(t)$ are, respectively, the triboelectric charge density, vacuum permittivity and separation distance, and $\Delta \sigma$, $d$ and $\varepsilon_{\mathrm{r}}$ are the induced charge density, thickness and relative permittivity of each dielectric layer. In the case of open-circuit conditions, there is no charge transfer, which means $\Delta \sigma$ is zero. Therefore, $V_{\text {oc }}$ is simplified by

$$
V_{\mathrm{oc}}=\frac{\sigma x(t)}{\varepsilon_{0}}
$$

As TENGs are fundamentally based on capacitive behavior, the concept of the displacement field $(D)$ can be applied in order to determine the relationship between the relative permittivity and the electric performance of TENGs. ${ }^{11}$ In a parallel plate capacitor, the triboelectric charge density $(\sigma)$ is equal to the magnitude of $D,{ }^{30}$ which is given by

$$
\sigma=\frac{Q}{A}=D=\varepsilon_{0} \varepsilon_{\mathrm{r}} E
$$

where $E$ is the electric field strength and $A$ is the surface area of the dielectric materials. Therefore, from the equation, the proportional relationship between $s$ and the relative permittivity $\left(\varepsilon_{\mathrm{r}}\right)$ is clarified. $V_{\mathrm{oc}}$ is therefore dependent on the relative permittivity of the material. ${ }^{26}$

A table of the relative permittivity of several oxide dielectric materials is shown in Fig. 2. The triboelectric series is considered as a basic reference to select proper materials for TENGs. From the triboelectric series, it is possible to estimate which side will be negatively or positively charged when a triboelectric

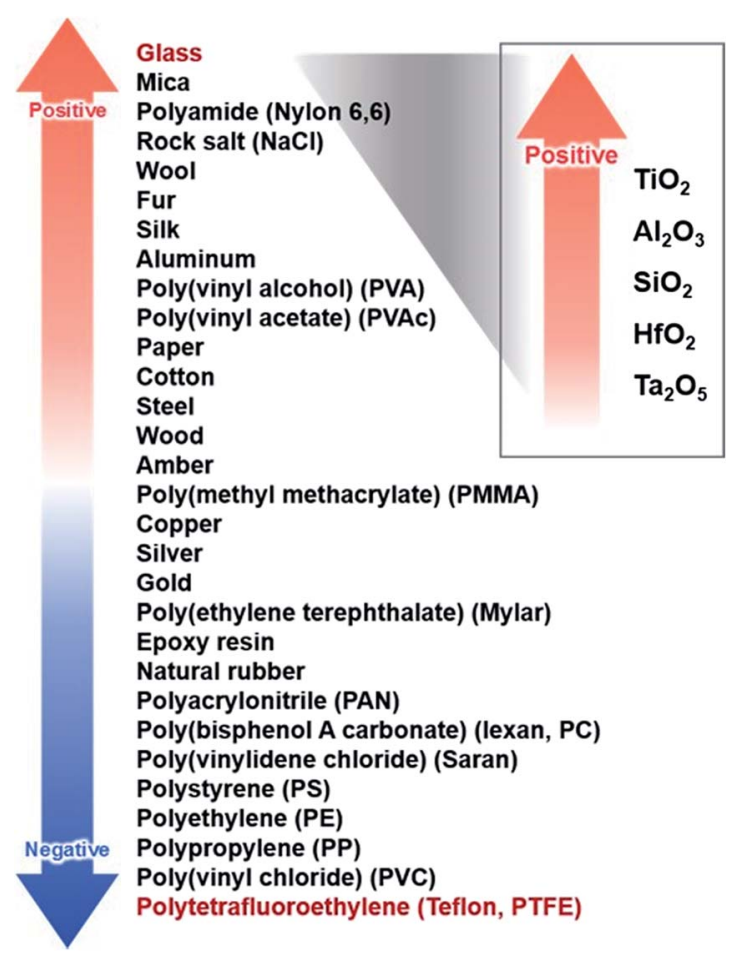

Fig. 2 A conventional triboelectric series and an experimentally determined triboelectric series of oxide dielectric materials. 
charge is generated by friction between two different materials. Since there is limited data for the above-mentioned oxide materials, a triboelectric series consisting of $\mathrm{SiO}_{2}, \mathrm{Al}_{2} \mathrm{O}_{3}, \mathrm{HfO}_{2}$, $\mathrm{Ta}_{2} \mathrm{O}_{5}$ and $\mathrm{TiO}_{2}$ was made experimentally. The series was made by comparing the measured $V_{\mathrm{oc}}$ values of the TENGs using 10 combinations of two oxide materials. All of the $V_{\text {oc }}$ data showed very low $V_{\text {oc }}$ values, from $0.1 \mathrm{~V}$ to $1.7 \mathrm{~V}$ (Fig. $\mathrm{S} 1 \dagger$ ), which means the triboelectric polarities of the above-mentioned oxide materials have very small differences. The $V_{\text {oc }}$ values were also measured with a reversed connection of the electrodes to make sure that the generated pulses were from the TENGs. The most positively charged oxide material was $\mathrm{TiO}_{2}$, followed by $\mathrm{Al}_{2} \mathrm{O}_{3}$, $\mathrm{SiO}_{2}$ and $\mathrm{HfO}_{2}$, and the most negatively charged oxide material was $\mathrm{Ta}_{2} \mathrm{O}_{5}$.

The oxide thin films with a thickness of $300 \mathrm{~nm}$ were used as the positive tribo-materials. PTFE film with a thickness of $50 \mu \mathrm{m}$ was used as the counter tribo-material. The electrical data for the fabricated TENGs are shown in Fig. 3. $V_{\text {oc }}$ was measured using a Keithley 6514B electrometer, and $I_{\mathrm{sc}}$ was measured using a Keithley 6485 picoammeter and a Tektronix DPO 2024 oscilloscope. The $V_{\text {oc }}$ values of $\mathrm{SiO}_{2}, \mathrm{Al}_{2} \mathrm{O}_{3}, \mathrm{HfO}_{2}, \mathrm{Ta}_{2} \mathrm{O}_{5}$ and $\mathrm{TiO}_{2}$ are, respectively, $50.2 \mathrm{~V}, 87.2 \mathrm{~V}, 109.3 \mathrm{~V}, 114.5 \mathrm{~V}$ and $124.1 \mathrm{~V}$ (Fig. 3a), and the $I_{\mathrm{sc}}$ values are $3.92 \mu \mathrm{A}, 5 \mu \mathrm{A}, 5.12 \mu \mathrm{A}$, $6.24 \mu \mathrm{A}$ and $14.88 \mu \mathrm{A}$ (Fig. $3 \mathrm{~b}$ ). Both $V_{\mathrm{oc}}$ and $I_{\mathrm{sc}}$ showed a general tendency to increase as the relative permittivity increases.

As shown in Fig. 4, the measured electrical data were plotted as a function of the relative permittivity and triboelectric polarity according to the organized triboelectric series. The maximum instantaneous power of the thin film (TF) TENGs was measured as $307.58 \mu \mathrm{W}, 322.86 \mu \mathrm{W}, 333.09 \mu \mathrm{W}, 346.29 \mu \mathrm{W}$ and
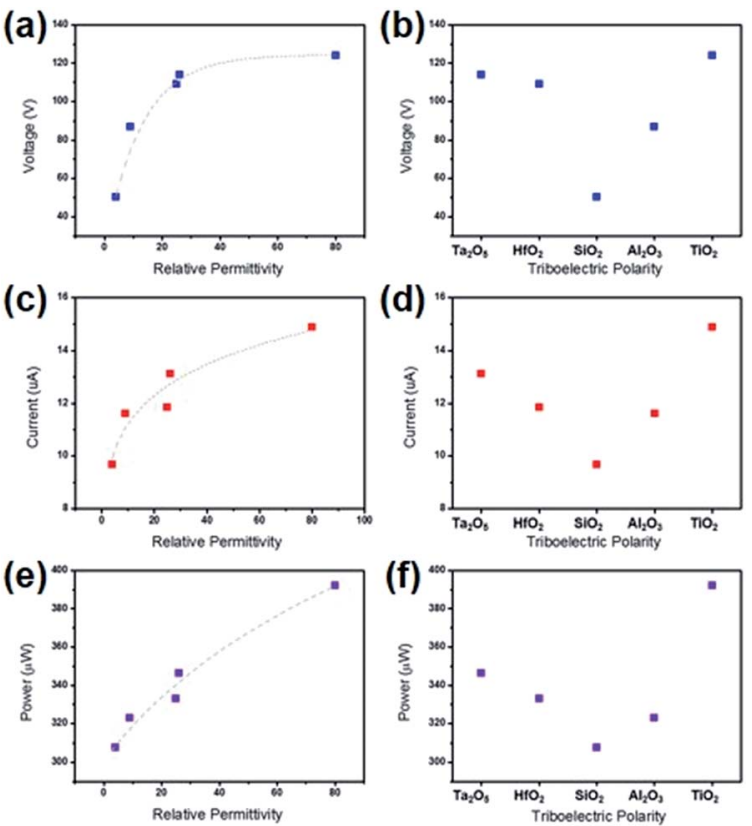

Fig. 4 Plotted $V_{\mathrm{oc}}, I_{\mathrm{sc}}$ and power data as a function of $(\mathrm{a}-\mathrm{c})$ relative permittivity and $(d-f)$ triboelectric polarity.

$392.08 \mu \mathrm{W}$ in order of relative permittivity. In contrast to the common understanding of the triboelectric series, the performance of the oxide TF TENGs does not follow the order of triboelectric polarity (Fig. $4 \mathrm{~b}, \mathrm{~d}$ and f). Instead, the higher the relative permittivity of the material, the better the performance
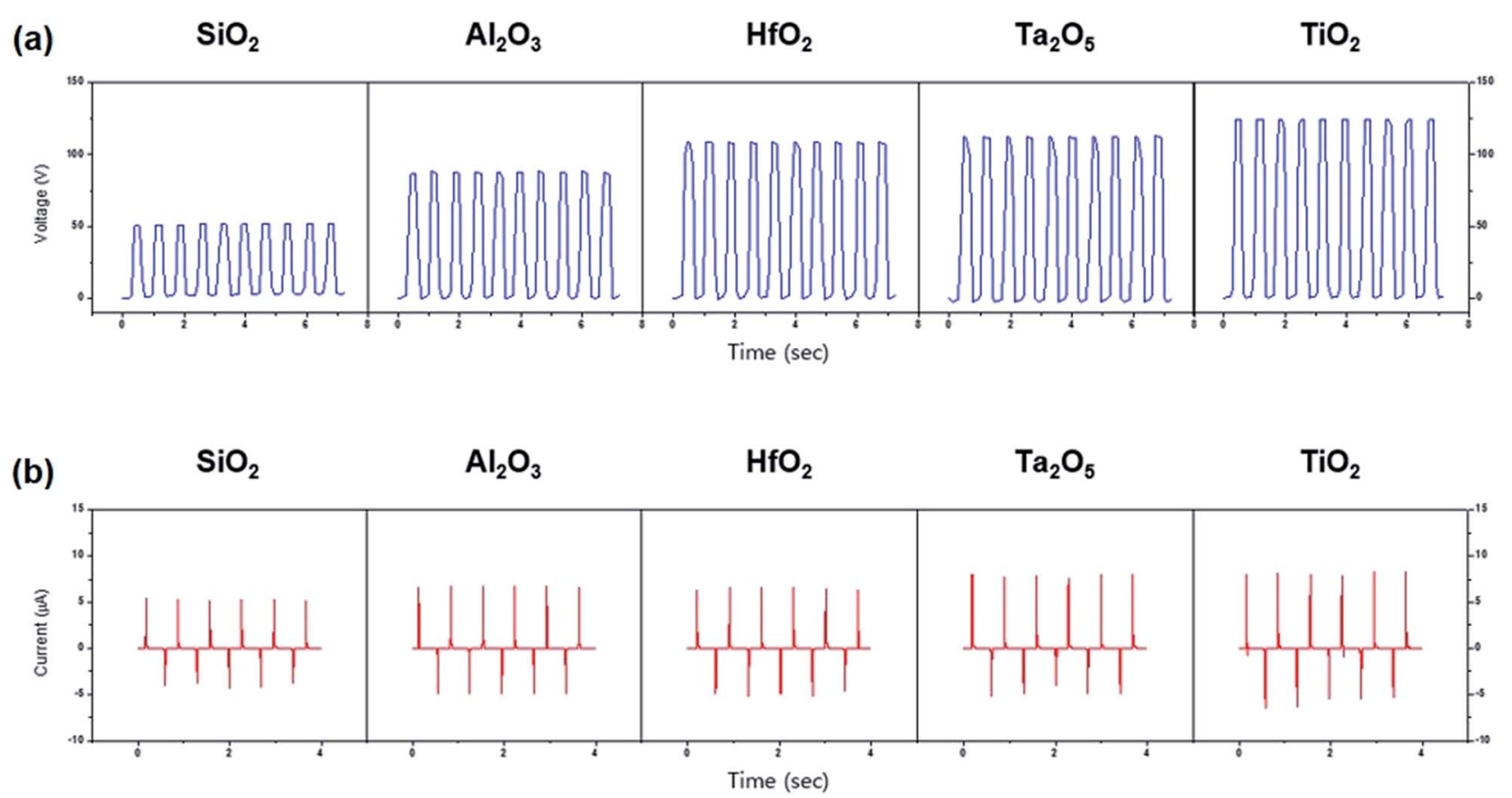

Fig. 3 Electrical output measurements. (a) $\mathrm{V}_{\mathrm{oc}}$ was measured using a Keithley $6514 \mathrm{~B}$ electrometer. The output voltages of $\mathrm{SiO}_{2}, \mathrm{Al}_{2} \mathrm{O}_{3}, \mathrm{HfO}_{2}$, $\mathrm{Ta}_{2} \mathrm{O}_{5}$ and $\mathrm{TiO}_{2}$ are, respectively, $50.2 \mathrm{~V}, 87.2 \mathrm{~V}, 109.3 \mathrm{~V}, 114.5 \mathrm{~V}$ and $124.1 \mathrm{~V}$. (b) Isc was measured using a Keithley 6485 picoammeter and a Tektronix DPO 2024 oscilloscope. The output currents of $\mathrm{SiO}_{2}, \mathrm{Al}_{2} \mathrm{O}_{3}, \mathrm{HfO}_{2}, \mathrm{Ta}_{2} \mathrm{O}_{5}$ and $\mathrm{TiO}_{2}$ are, respectively, $9.68 \mu \mathrm{A}, 11.6 \mu \mathrm{A}, 11.84 \mu \mathrm{A}, 13.12$ $\mu \mathrm{A}$ and $14.88 \mu \mathrm{A}$. 
achieved (Fig. 4a, c and e). This result indicates that the relative permittivity is considered to be a more dominant factor than the triboelectric polarity which affects the electrical output of TENGs. Consequently, when the variation of triboelectric polarity is small, the electrical output is more dependent on the relative permittivity than the triboelectric polarity.

The same principle can be applied to composite materials. PMMA was chosen as a matrix for this experiment as it can be made into composites with ease, and it is located on the positive side of the triboelectric series. The fillers for the composites were $\mathrm{SiO}_{2}, \mathrm{Al}_{2} \mathrm{O}_{3}, \mathrm{HfO}_{2}$ and $\mathrm{TiO}_{2}$ nanoparticles (NPs). The morphologies of the NPs were observed using a scanning electron microscope (SEM) (Fig. S2 $\dagger$ ). The electrical data for the composite TENGs are shown in Fig. 5. The $V_{\text {oc }}$ values of the TENGs using PMMA composites consisting of $\mathrm{SiO}_{2} \mathrm{NPs}, \mathrm{Al}_{2} \mathrm{O}_{3}$ $\mathrm{NPs}, \mathrm{HfO}_{2} \mathrm{NPs}$ and $\mathrm{TiO}_{2} \mathrm{NPs}$ are, respectively, $84.7 \mathrm{~V}, 86.3 \mathrm{~V}$, 97.9 $\mathrm{V}$ and $90.7 \mathrm{~V}$, while pristine PMMA had a $V_{\text {oc }}$ of $47.5 \mathrm{~V}$ (Fig. 5a). $I_{\mathrm{sc}}$ showed a similar tendency to $V_{\mathrm{oc}}$, with values of $6.32 \mu \mathrm{A}, 8.88 \mu \mathrm{A}, 9.28 \mu \mathrm{A}$ and $8.16 \mu \mathrm{A}$, while pristine PMMA had an $I_{\mathrm{sc}}$ of $3.76 \mu \mathrm{A}$ (Fig. 5b). The maximum instantaneous power data were measured as $153.63 \mu \mathrm{W}, 200.04 \mu \mathrm{W}, 216.36 \mu \mathrm{W}$,
$236.33 \mu \mathrm{W}$ and $262.94 \mu \mathrm{W}$, respectively (Fig. 5e). The results generally show a similar tendency to the experiment using pure oxide thin films, with some exceptions (Fig. 5c-e). Since the composite materials exhibit more complex structures compared to the pure materials, many factors such as the roughness of the surface and/or the effects generated at the interface between the fillers and the matrix can also affect the electrical outputs and results, with exceptions. However, both sets of results from the thin films and composites were well-matched with our theoretical prediction of the dependence of performance on the permittivity of the oxide materials.

\section{Experimental}

\section{Preparation of the tribo-materials}

A thin film of $\mathrm{Al}(60 \mathrm{~nm})$ was deposited on a purchased PTFE film $(50 \mu \mathrm{m})$ using a thermal evaporator. $\mathrm{Al}_{2} \mathrm{O}_{3}, \mathrm{HfO}_{2}, \mathrm{Ta}_{2} \mathrm{O}_{5}$ and $\mathrm{TiO}_{2}$ thin films $(300 \mathrm{~nm})$ were deposited by sputtering on a doped silicon substrate. The working power was $1000 \mathrm{~W}$ at $10^{-8}$ Torr. The $\mathrm{SiO}_{2}$ thin film $(300 \mathrm{~nm})$ was synthesized by oxidizing a Si wafer. As shown in Fig. S3, $\uparrow$ the composition of
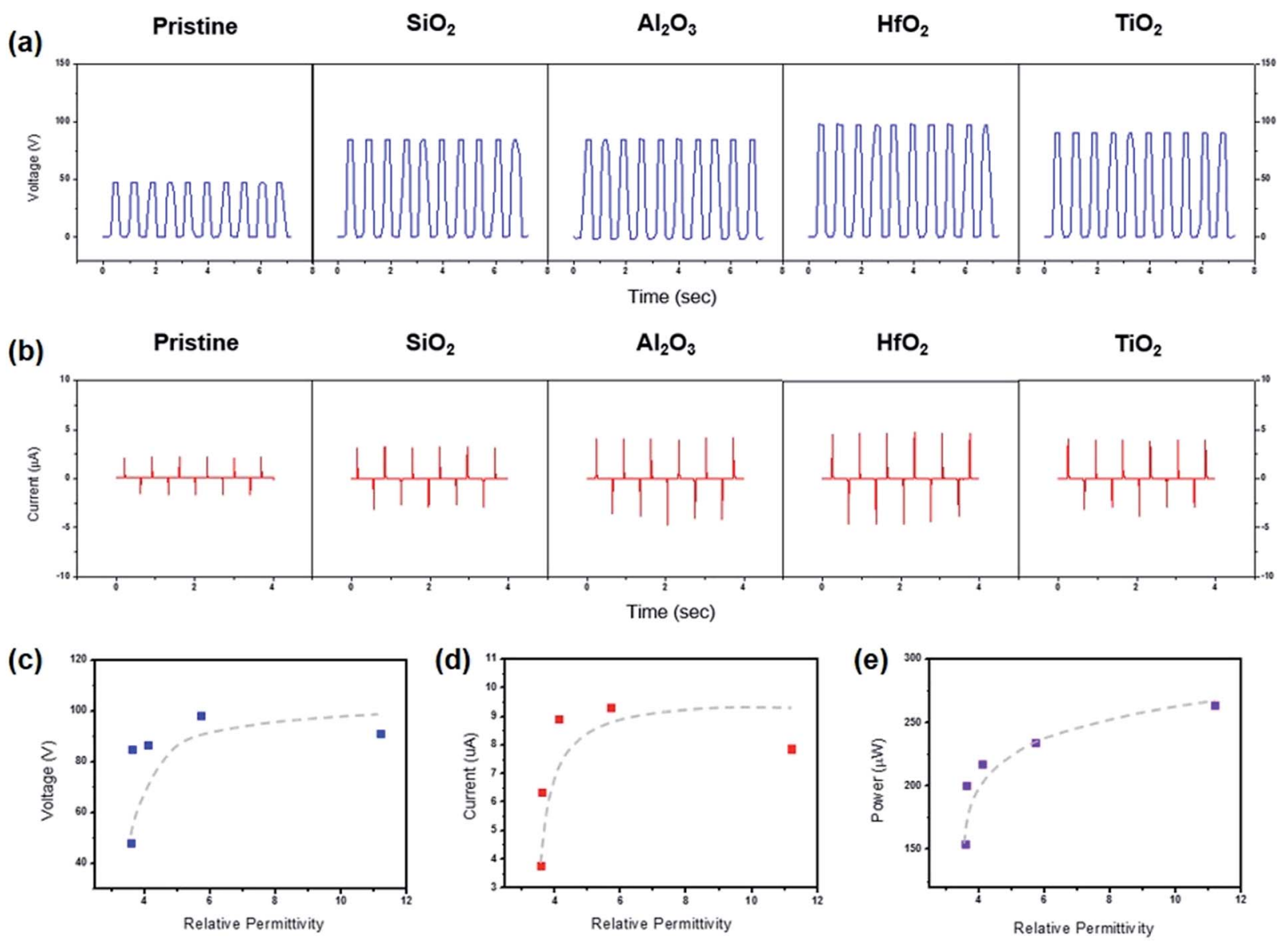

Fig. 5 Electrical data for the composite TENGs. (a) $V_{\text {oc }}$ was measured using a Keithley $6514 \mathrm{~B}$ electrometer. The output voltages for pristine $\mathrm{PMMA}$ and the composites consisting of $\mathrm{SiO}_{2}, \mathrm{Al}_{2} \mathrm{O}_{3}, \mathrm{HfO}_{2}$ and $\mathrm{TiO}_{2}$ nanoparticles are, respectively, $47.5 \mathrm{~V}, 84.7 \mathrm{~V}, 86.3 \mathrm{~V}, 97.9 \mathrm{~V}$ and $90.7 \mathrm{~V}$. (b) Isc was measured using a Keithley 6485 picoammeter and a Tektronix DPO 2024 oscilloscope. The output currents for pristine PMMA and the composites consisting of $\mathrm{SiO}_{2}, \mathrm{Al}_{2} \mathrm{O}_{3}, \mathrm{HfO}_{2}$ and $\mathrm{TiO}_{2}$ nanoparticles are, respectively, $3.76 \mu \mathrm{A}, 6.32 \mu \mathrm{A}, 8.88 \mu \mathrm{A}, 9.28 \mu \mathrm{A}$ and $8.16 \mu \mathrm{A}$. (c, d and e) $V_{\mathrm{oc}}, I_{\mathrm{sc}}$ and power as a function of relative permittivity, respectively. 
each oxide material was analyzed by X-ray photoelectron spectrometry (XPS). The PMMA composite films were synthesized by the following method. $\mathrm{SiO}_{2}(\varepsilon=3.9), \mathrm{Al}_{2} \mathrm{O}_{3}(\varepsilon=9), \mathrm{HfO}_{2}(\varepsilon=25)$ and $\mathrm{TiO}_{2}(\varepsilon=80)$ nanoparticles were purchased from Sigma Aldrich. For uniform composite films, the oxide nanoparticles were dispersed in ethanol and sonicated for $30 \mathrm{~min}$. Each dispersion solution was mixed with PMMA 495 and mechanically stirred at $348 \mathrm{~K}$ for $6 \mathrm{~h}$ in order to evaporate the ethanol completely. The volume ratio of nanoparticles to PMMA was $1: 10$. Each suspension was spin-coated on a doped Si wafer and baked at $453 \mathrm{~K}$ for $2 \mathrm{~min}$.

\section{Characterization}

The deposition of the oxide thin films was confirmed by X-ray photoelectron spectroscopy (XPS) with a K-alpha (Thermo VG, $\mathrm{UK}$ ) instrument at room temperature using a monochromatic $\mathrm{Al}$ $\mathrm{X}$-ray source at $12 \mathrm{kV}$ and $3 \mathrm{~mA}$. The sample analysis chamber of the XPS instrument was maintained at a pressure of $4.8 \times 10^{-9}$ mbar. The electrical outputs of the TENGs were measured using a Keithley 6485 picoammeter, a Tektronix DPO 2024 oscilloscope and a Keithley 6514B electrometer for low-noise and precise current/voltage measurements under a vertical load of 3-5 $\mathrm{N}$ with a frequency of $1.25 \mathrm{~Hz}$. The separation distance between two plates was $4 \mathrm{~mm}$.

\section{Conclusions}

The influence of the relative permittivity of dielectric materials on the performance of TENGs, by controlling the positive plate with various oxide materials, has been demonstrated. $\mathrm{SiO}_{2}\left(\varepsilon_{\mathrm{r}}=3.9\right)$, $\mathrm{Al}_{2} \mathrm{O}_{3}\left(\varepsilon_{\mathrm{r}}=9\right), \mathrm{HfO}_{2}\left(\varepsilon_{\mathrm{r}}=25\right), \mathrm{Ta}_{2} \mathrm{O}_{5}\left(\varepsilon_{\mathrm{r}}=26\right)$ and $\mathrm{TiO}_{2}\left(\varepsilon_{\mathrm{r}}=80\right)$ were selected as pure oxide tribo-materials. From the most negative to the most positive, the oxides are listed in the order of $\mathrm{Ta}_{2} \mathrm{O}_{5}, \mathrm{HfO}_{2}, \mathrm{SiO}_{2}, \mathrm{Al}_{2} \mathrm{O}_{3}$ and $\mathrm{TiO}_{2}$. PMMA composite TENGs were also fabricated using $\mathrm{SiO}_{2}, \mathrm{Al}_{2} \mathrm{O}_{3}, \mathrm{HfO}_{2}$ and $\mathrm{TiO}_{2} \mathrm{NPs}$. The measured $V_{\mathrm{oc}}, I_{\mathrm{sc}}$ and power values of the TENGs showed a general tendency to increase with an increase in the relative permittivity, while scattered data were observed as a function of the triboelectric polarity. In other words, the relative permittivity is considered to be a more dominant factor than the triboelectric polarity in this study. This work provides a better understanding of the factors affecting the performance of TENGs from the view of the materials. By considering the relative permittivity, it will be possible to broaden the range of selectable tribo-materials and the subsequent applications.

\section{Conflicts of interest}

There are no conflicts to declare.

\section{Acknowledgements}

This work is supported by the National Research Foundation of Korea (NRF) grant funded by the Korean government (MSIP) (No. 2017R1A2B3011586), the Nano-Material Technology Development Program through the National Research
Foundation of Korea (NRF) funded by the Ministry of Education, Science and Technology (2014M3A7B4051594), the third Stage of Brain Korea 21 Plus Project in 2017, and the Yonsei University Yonsei-SNU Collaborative Research Fund of 2014.

\section{References}

1 Z. Zhao, X. Pu, C. Du, L. Li, C. Jiang, W. Hu and Z. L. Wang, ACS Nano, 2016, 10, 1780.

2 Y. Yang, G. Zhu, H. Zhang, J. Chen, X. Zhoung, Z. H. Lin, Y. Su, P. Bai, X. Wen and Z. L. Wang, ACS Nano, 2013, 6, 9461.

3 X. Wang, S. Niu, Y. Yin, F. Yi, S. You and Z. L. Wang, Adv. Energy Mater., 2015, 5, 1501467.

4 D. Bhatia, W. Kim, S. Lee, S. W. Kim and D. Choi, Nano Energy, 2017, 33, 515.

5 F. R. Fan, Z. Q. Tian and Z. L. Wang, Nano Energy, 2012, 1, 328.

6 Z. L. Wang, L. Lin, J. Chen, S. Niu and Y. Zi, Triboelectric Nanogenerators, Springer, Switzerland, 2016.

7 Y. Zi, J. Wang, S. Wang, S. Li, Z. Wen, H. Guo and Z. L. Wang, Nat. Commun., 2016, 7, 10987.

8 S. Wang, L. Lin and Z. L. Wang, Nano Lett., 2012, 12, 6339. 9 S. Niu and Z. L. Wang, Nano Energy, 2015, 14, 161.

10 S. Niu, S. Wang, L. Lin, Y. Liu, Y. S. Zhou, Y. Hu and Z. L. Wang, Energy Environ. Sci., 2013, 6, 3576.

11 S. Niu, Y. Liu, S. Wang, L. Lin, Y. S. Zhou, Y. Hu and Z. L. Wang, Adv. Mater., 2013, 25, 6184.

12 B. Yang, W. Zeng, Z. H. Peng, S. R. Liu, K. Chen and X. M. Tao, Adv. Energy Mater., 2016, 6, 1600505.

13 S. M. Kim, J. Ha and J. B. Kim, Integr. Ferroelectr., 2016, 176, 283.

14 S. Wang, L. Lin, Y. Xie, Q. Jing, S. Niu and Z. L. Wang, Nano Lett., 2013, 13, 2226.

15 G. Zhu, J. Chen, Y. Liu, P. Bai, Y. S. Zhou, Q. Jing, C. Pan and Z. L. Wang, Nano Lett., 2013, 13, 2282.

16 Y. Yang, Y. S. Zhou, H. Zhang, Y. Liu, S. Lee and Z. L. Wang, Adv. Mater., 2013, 25, 6594.

17 Y. Yang, H. Zhang, J. Chen, Q. Jing, Y. S. Zhou, X. Wen and Z. L. Wang, ACS Nano, 2013, 7, 7342.

18 S. Niu, Y. Liu, S. Wang, L. Lin, Y. S. Zhou, Y. Hu and Z. L. Wang, Adv. Funct. Mater., 2014, 24, 3332.

19 S. Wang, Y. Xie, S. Niu, L. Lin and Z. L. Wang, Adv. Mater., 2014, 26, 2818.

20 B. Meng, W. Tang, Z. H. Too, X. Zhang, M. Han, W. Liu and H. Zhang, Energy Environ. Sci., 2013, 6, 3235.

21 F. R. Fan, L. Lin, G. Zhu, W. Z. Wu, R. Zhang and Z. L. Wang, Nano Lett., 2012, 12, 3109.

22 L. Lin, S. Wang, Y. Xie, Q. Jing, S. Niu, Y. Hu and Z. L. Wang, Nano Lett., 2013, 13, 2916.

23 S. Niu, Y. Liu, X. Chen, S. Wang, Y. S. Zhou, L. Lin, Y. Xie and Z. L. Wang, Nano Energy, 2015, 12, 760.

24 G. Zhu, Z. H. Lin, Q. Jing, P. Bai, C. Pan, Y. Yang, Y. Zhou and Z. L. Wang, Nano Lett., 2013, 13, 847.

25 Z. H. Lin, G. Cheng, W. Wu, K. C. Pradel and Z. L. Wang, ACS Nano, 2014, 8, 6440.

26 J. Chen, H. Guo, X. He, G. Liu, Y. Xi, H. Shi and C. Hu, ACS Appl. Mater. Interfaces, 2016, 8, 736. 
27 X. J. Zhao, G. Zhu and Z. L. Wang, ACS Appl. Mater. Interfaces, 2015, 7, 6025.

28 J. Zhong, Q. Zhong, F. Fan, Y. Zhang, S. Wang, B. Hu and Z. L. Wang, Nano Energy, 2013, 2, 491.
29 Z. H. Lin, Y. Xie, Y. Yang, S. Wang, G. Zhu and Z. L. Wang, ACS Nano, 2013, 7, 4554.

30 R. Kronig, Textbook of Physics, Pergamon Press London, New York, 1959. 